Astalos records a somewhat similar case, but, as there was no diplopia, Hess's operation was performed on both sides with a satisfactory result. ${ }^{(1)}$

Peters describes a case in which he operated by Pagenstecher's method,(2) and Braunschweig operated on the brother of Peters' case. ${ }^{(3)}$

These are the only references to operation in cases of myasthenia gravis that we have been able to find and it would be interesting to know if there are many similar cases which perhaps have not been recorded.

It appears to be recognized that cases of myasthenia gravis do occur in which the symptoms either remain confined to the eye muscles $^{(4)}$ or spread to other parts of the body only after long intervals of months or even years ${ }^{(5)}$; so that it would seem worth while in all but very acute cases to consider operative treatment where ptosis is a prominent and disabling feature.

Addendum by Mr. W. H. KiEP.

Hess's operation was performed on left upper eyelid on May 6 , 1926, the drooping of the lid being over-corrected. Patient made an uneventful recovery and when I saw him some six months later asked to have the other eye done. On account of the persistent diplopia, however, it was not considered wise to do the right side.

\title{
REFERENCES
}

1. Aszalos, E.-Klin. Monatsbl, f. Augenheilk., Bd. 73, SS. 445-447, 1924.

2 and 3.-Peters.--Ueber Myasthenia und Ptosis. Korresp. Blätt. d. Allg. Mecklenburg. Aerztvercins, Nr. 262.

4. Jaffey.-Ophthalmic Year Book, (Chicago), Vol. XXI, p. 47, 1925.

5. Taylor.-Trans. Ophthal. Soc. U.K., Vol. XXXVIII, p. 168, 1918.

\section{SERIOUS HAEMORRHAGE FROM THE CONJUNCTIVA IN AN INFANT, FOLLOWING INSTILLATION OF SILVER NITRATE SOLUTION}

BY

\author{
J. G. F. Heal, M.I., C.M., London.
}

THE child was born at 10.30 a.m. on April 20, 192\%. As the mother was believed to have gonorrhoea, the medical attendant ordered 1.5 per cent. solution of silver nitrate to be dropped into the infant's eyes three times a day.

The child was first seen by me thirty-four hours after birth. It was ascertained that the silver nitrate had been instilled into each eye on at least five occasions. The lids of both eyes were slightly swollen, and the margins hyperaemic, The right eye: 
there was a slight sanguineous discharge from this eye, the conjunctiva of the lids was denuded of epithelium in places which showed as oozing areas; the cornea was steamy. The left eye : the conjunctival sac was filled with a firm blood clot, which extended behind both lids, covered the cornea, and protruded through the palpebral fissure. Blood was oozing from between the lids. At first a birth injury was suspected, as forceps had been used, but this was negatived by observing that the tension of the eye was normal, and that the condition of the right eye could not have been due to injury. The blood clot was not disturbed, and all interference with the eye was stopped.

Throughout the 22nd the left eye continued a slight oozing, the right eye did not bleed. A pressure bandage was ordered for the left eye.

During the 23rd the oozing of blood from the left eye became worse. The pressure bandage produced no effect, but became soaked with blood. The conjunctival surface of the lids in the right eye showed patches of yellowish adherent exudate, probably fibrin. The bleeding from this eye had permanently stopped. The child looked shrunken, it was getting weak, and refusing its food. There was every reason to believe that if the haemorrhage were not checked the child would die.

On the $23 \mathrm{rd}$, at 8.30 p.m., the child was anaesthetized with chloroform. After removing a firm shrunken blood clot from the left conjunctival sac, the cornea was found steamy over its whole surface, and showed what appeared to be a loss of substance over a linear area concentric with, and just within the limbus, at its lower and outer quadrant. The upper lid showed an extensive raw area, oozing blood from a number of points. This area extended over the outer three-quarters of the conjunctival surface of the everted lid. 'The oozing was mostly in the region of the subtarsal furrow. The bleeding points were sealed by touching them with the blunt end of a probe heated in a spirit lamp. About ten applications of the probe were made. The exact points of haemorrhage were rendered more readily manifest br continually sluicing the surface with lotion from an undine. Ail bleeding was stopped, vaseline was inserted between the lids, and the eyes left uncovered. The right cornea was steamy, but rather less so than the left. The lower lids were comparatively little affected in either eye. No further bleeding occurred, and the child made a good recovery.

When seen five weeks later the corneae were perfectly clear except for a faint trace of opacity at the lower and peripheral part of the left. There was no entropion of the lid which had been cauterized, and both lids appeared to be quite normal. The child had developed fixation. There was no nystagmus. 
In this case gonorrhoea could be negatived by the complete absence of any purulent discharge and the slight and transient nature of the conjunctivitis.

No history of haemophilia could be obtained from either parent, nor had they any knowledge of its occurrence in their respective families.

\section{ANNOTATIONS}

\section{A Great Neurological Triad}

The publication of Sherrington's lectures on "The Integrative Action of the Central Nervous System" in the year 1906 was one of the most important milestones on the road of neurological research. In that volume was codified, for the first time, all the researches which Sherrington and his pupils had been carrying on over a long series of years. The characteristics of the spinal reflex were defined and we were allowed to see, as in a glass darkly, something of the working of the central nervous system. It would be impossible within the limits of a short annotation to enumerate all the various lines of research which have been inspired by Sherrington's great work, but, for two reasons, the present would seem to be a suitable time to refer to two of the greatest branches which have grown from the tree which he then planted. The first can only be referred to with deep regret. The recent death of Professor Magnus of Utrecht has been a very grievous loss to physiology. One of the most brilliant of Sherrington's disciples, he was the inspiration of the Dutch school of neurological research, and his recent book "Körperstellung" does for the mid-brain region what Sherrington's work had already done for the spinal cord. It has established itself as one of the classics of neurology, worthy to take its place beside "The Integrative Action of the Central Nervous System."

The second of the great branches which has sprung from this common stem is Pavlov's work on "Conditioned Reflexes." What Sherrington did for the spinal cord and Magnus for the mid-brain, Pavlov has essayed to do for the cortex cerebri. Hitherto, in England, we have only known somewhat vaguely of the work done by the distinguished Petrograd physiologist on these lines. Most of the papers have been in a language not readily available to the ordinary Englishman. With the assistance of a grant from the Royal Society, Dr. Anrep has now published a translation of Pavlov's lectures in which are summarized the researches which he and his pupils have been carrying on for the 